\title{
Mineração
}

\section{Influência de variáveis operacionais no desempenho de classificador aerodinâmico}

\author{
(Influence of operating variables on the performance of a \\ dynamic air classifier)
}

\author{
Luís Marcelo Marques Tavares \\ Laboratório de Tecnologia Mineral, Programa de Engenharia Metalúrgica e de Materiais, COPPE/UFRJ \\ E-mail: tavares@metalmat.ufrj.br \\ Emerson Reikdal da Cunha \\ Laboratório de Tecnologia Mineral, Programa de Engenharia Metalúrgica e de Materiais, COPPE/UFRJ \\ E-mail:emerson@metalmat.ufr.br \\ Salvador Luiz de Almeida \\ Centro de Tecnologia Mineral, CETEM/MCT \\ E-mail:salmeida@cetem.gov.br
}

\section{Resumo}

A classificação dinâmica a seco ocupa uma posição de destaque em circuitos de moagem de cimento e de diversos minerais industriais. Uma importante aplicação recente desse equipamento tem sido na adequação da proporção de material pulverulento $(<75 \mu \mathrm{m})$ contido em agregados miúdos (areias) para a construção civil, produzidos por britagem. O presente trabalho investiga a influência de uma série de variáveis no desempenho de um classificador Sturtevant, que opera em escala-piloto, visando a fornecer subsídios para a modelagem matemática. É demonstrado que o seu desempenho é significativamente influenciado pelo teor de umidade, pela freqüência de rotações e pela posição dos elementos de rejeição, sendo, apenas, marginalmente, afetado pela forma de partícula e taxa de alimentação de sólidos, dentro do intervalo estudado.

Palavras-chave: Classificação a seco, avaliação do desempenho, eficiência.

\begin{abstract}
Dynamic air classification occupies a central position in the grinding circuits of cement and several other industrial minerals. An important recent application of this device is in the reduction of the proportion of fine $(<75 \mu \mathrm{m})$ material contained in fine aggregate for construction that is produced by crushing. The present paper analyzes the influence of a number of variables on the performance of a pilot-scale Sturtevant classifier, aiming at providing data for mathematical modeling. It is demonstrated that the performance of the classifier is significantly influenced by feed moisture content, rotor frequency and the position of the rejection elements, being just marginally influenced by particle shape and the feed rate, within the range of the studied conditions.
\end{abstract}

Keywords: Dry classification, performance evaluation, efficiency. 


\section{Introdução}

A classificação dinâmica a seco (aerodinâmica) ocupa uma posição de destaque em circuitos de cominuição nas indústrias cimenteira, química e de fármacos. Na indústria mineral, ela é empregada com freqüência como parte da moagem fina de minerais industriais. Uma outra aplicação mais recente tem sido na produção de areia manufaturada para a construção civil, na qual ela é uma importante alternativa na remoção parcial da fração fina do produto britado [1].

Classificadores (ou separadores) dinâmicos empregados na indústria são classificados de acordo com os mecanismos adotados na separação em três tipos, também denominadas gerações. Nos separadores de primeira geração, a alimentação se dá por meio de um prato distribuidor, cuja freqüência de rotações é a mesma do ventilador e das palhetas, de maneira que o fluxo de ar, no separador, não pode ser controlado independentemente. Nesse separador, a ventilação é interna e a separação dos finos da corrente do fluido é realizada dentro do próprio separador, não sendo muito eficiente. Exemplos desse tipo de separador são o Whirlwind ${ }^{\circledR}$ da Sturtevant e o separador aerodinâmico da Furlan. Os separadores de segunda geração se caracterizam pelo uso de ventilação externa, que permite o controle independente do fluxo de ar ao separador. Esses separadores também permitem uma melhor separação dos finos da corrente do fluido pelo uso de pequenos ciclones externos. Os separadores de terceira geração se diferenciam dos de segunda pelo uso de uma gaiola na qual as palhetas são colocadas. Isso permite um aumento da área efetiva de separação, a qual é, comparativamente, pequena nos separadores de primeira e segunda geração. A alimentação não se dá mais em um prato distribuidor, mas sobre a gaiola. Exemplos desse tipo de separador em uso no Brasil são o SEPOL ${ }^{\circledR}$ da Polysius, o Sturtevant $\mathrm{SD}^{\circledR}$ da Sturtevant e o Presep $\mathrm{VTP}^{\circledR}$ da PSP Engineering.

Um diagrama esquemático de um separador dinâmico de primeira geração é apresentado na Figura 1. A separação de partículas no interior de separadores dinâmicos é o resultado da ação das forças centrífuga, gravitacional e de arraste do fluido (tipicamente o ar). O material que entra através da calha de alimentação é sujeito à ação da força centrífuga, que projeta as partículas grossas do prato dispersor na direção do fluxo de ar. Devido à ação da gravidade, as partículas grossas caem, sendo coletadas no cone de grossos. As partículas finas, por outro lado, são arrastadas pelo fluxo ascendente do fluido produzido pelo ventilador (palhetas fixas). Durante essa separação secundária, partículas grossas ainda remanescentes não são capazes de acompanhar o fluxo de ar enquanto contorna as palhetas (reguláveis) em movimento, caindo, também, para dentro do cone de grossos. Os finos que são capazes de passar com sucesso continuam a se deslocar através do ventilador para dentro do cone dos finos. Ainda que alguns estudos tenham analisado em algum detalhe o complexo escoamento do fluido e o movimento de partículas no interior do equipamento [2], modelos matemáticos de simulação da separação ainda não se encontram amplamente disponíveis para esses equipamentos [3-5].
O presente trabalho investiga a influência de várias variáveis operacionais no desempenho de um separador de primeira geração em operação em escalapiloto, com vistas a fornecer subsídios para a modelagem matemática desses classificadores.

\section{Desenvolvimento experimental}

\subsection{Materiais}

As amostras utilizadas no estudo são de produtos de britagem, passantes em peneira de 4,8 mm, provenientes da Pedra Sul Mineração Ltda (Matias Barbosa, MG). A rocha, de origem metamórfica, e classificada como granulito, é composta, predominantemente, por feldspatos alcalinos, plagioclásio, quartzo e hiperstênio [6].

As distribuições granulométricas das amostras são apresentadas na Figura 2. Ainda que de mesma composição mineralógica e distribuições granulométricas semelhantes, as amostras analisadas apresentam diferentes formas de partículas, resultado do uso de diferentes processos de britagem [7]. A Tabela

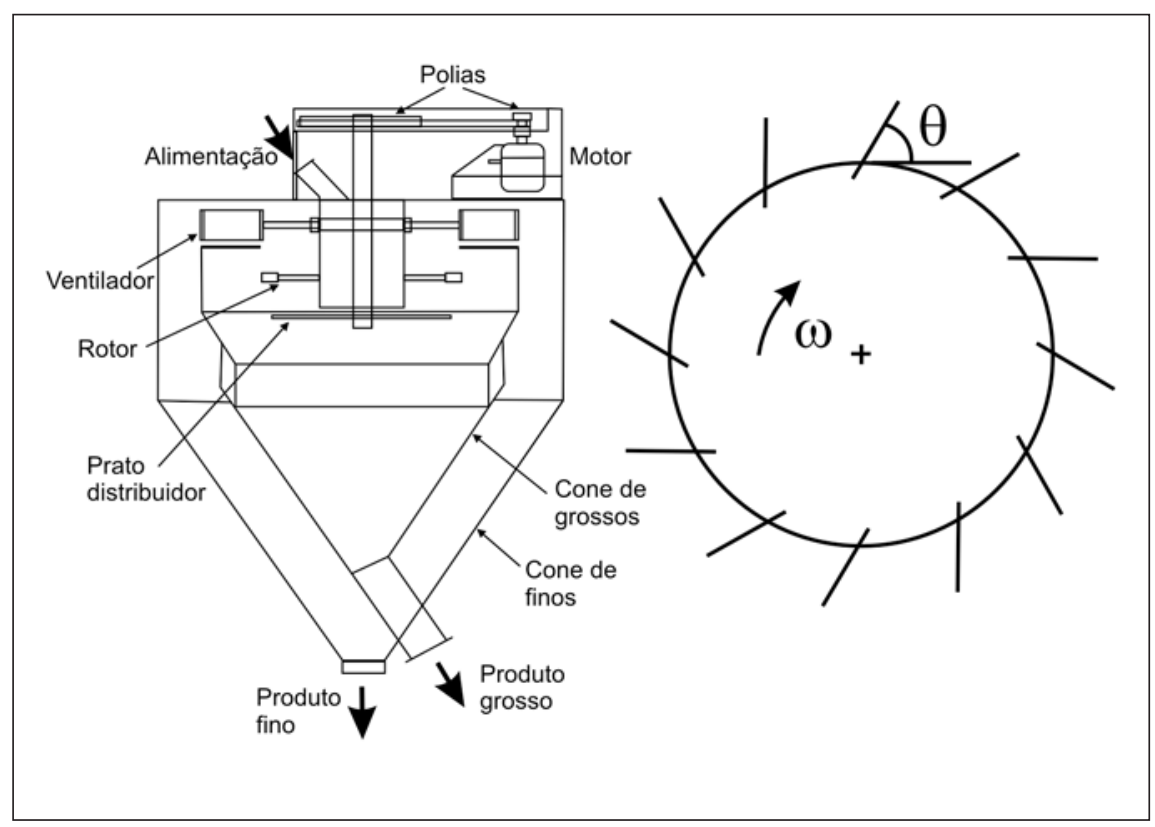

Figura 1 - Diagrama esquemático do classificador dinâmico a seco (esquerda) e do rotor, indicando o ângulo das palhetas $(\theta)$ e a direção de rotação (direita). 
Luís Marcelo Marques Tavares et al.

1 compara os parâmetros de forma das partículas, obtidos a partir de análises de imagens de microscopia ótica. A esfericidade é definida como a razão entre o produto de $4 \pi$ e a área projedada de cada partícula pelo quadrado do seu perímetro, enquanto a razão de aspecto descreve a razão entre o comprimento e a largura de uma partícula, determinados a partir de imagens bidimensionais [7]. A massa específica da rocha, determinada por picnometria, é igual a $2,80 \mathrm{~g} / \mathrm{cm}^{3}$.

\subsection{Equipamento}

$\mathrm{O}$ aparelho usado nos experimentos foi um separador dinâmico de primeira geração, do tipo Sturtevant. Um diagrama esquemático do classificador, operado em circuito aberto em escala-piloto, é apresentado na Figura 1. Nesse aparelho, não existe controle independente do prato dispersor e do rotor, movendo-se ambos à mesma freqüência. O classificador, que apresenta capacidade nominal de $200 \mathrm{~kg} / \mathrm{h}$, é equipado com um rotor que mede $253 \mathrm{~mm}$ de diâmetro, ao qual são fixadas 12 palhetas (também chamados elementos de rejeição) (Figura 1). A alimentação é realizada com o auxílio de um alimentador vibratório e um silo, que permitem a manutenção da taxa de alimentação durante todo o período de execução do ensaio, dentro de $\pm 10 \%$ do valor estabelecido.

\subsection{Procedimento experimental}

O primeiro passo no trabalho experimental consistiu do ajuste da freqüência de rotações do rotor (pela seleção do diâmetro adequado da polia do rotor) e da posição (ângulo) das palhetas.

Para cada material ensaiado, o procedimento experimental empregado consistiu da separação de um lote de aproximadamente $10 \mathrm{~kg}$ de amostra (previamente seca em estufa), controle de umidade pela adição (ou não) de água, seguido de homogeneização em um misturador em $\mathrm{V}$ pelo período de 20 minutos. Ime-



Figura 2 - Análises granulométricas das amostras ensaiadas.

Tabela 1 - Parâmetros de forma de partículas por microscopia ótica [7].

\begin{tabular}{c|c|c}
\hline Material & $\begin{array}{c}\text { Esfericidade } \\
\text { média }\end{array}$ & $\begin{array}{c}\text { Razão de } \\
\text { aspecto média }\end{array}$ \\
\hline Produto de britadores cônicos & 0,664 & 0,652 \\
\hline Produto de britadores de impacto & 0,706 & 0,678 \\
\hline
\end{tabular}

diatamente após a mistura, a alimentação era levada ao silo do alimentador vibratório e executado o ensaio.

Após a realização dos ensaios, os produtos foram pesados, a fim de estabelecer o balanço de massas. Amostras dos produtos grosso e fino de cada ensaio foram coletadas, quarteadas e analisadas por peneiramento pelo método híbrido (úmido/seco) em um peneirador Ro-Tap ${ }^{\circledR}$, usando uma série de peneiras de 4,75 até $0,037 \mathrm{~mm}$, que segue uma progressão geométrica com razão igual a $\sqrt{2}$. Essas informações foram utilizadas no cálculo das curvas de partição (Tromp) dos ensaios. Essas curvas podem ser calculadas a partir de diferentes estratégias [4]. No presente estudo, os coeficientes de partição para o produto grosso $\left(E_{u i}\right)$ foram calculados a partir das equações

$E_{u i}=100 \frac{W_{u i} Y}{\hat{W}_{f i}}$

na qual $W_{u i}$ e $\hat{W}_{i f}$ são as distribuições granulométricas do produto underflow (grosso) e da alimentação (reconstituída), respectivamente, e o rendimento $Y$ de produto grosso é dado por

$$
Y=\frac{\sum_{i=1}^{N}\left(W_{f i}-W_{o i}\right)\left(W_{u i}-W_{o i}\right)}{\sum_{i=1}^{N}\left(W_{u i}-W_{o i}\right)^{2}}
$$

sendo $W_{o i}$ e $W_{f i}$ as análises granulométricas do produto fino e da alimentação, respectivamente, e $N$ é o número de intervalos de tamanhos analisados. 


\section{Resultados e discussão \\ 3.1 Avaliação desempenho classificador}

do

A curva de Tromp é a ferramenta mais poderosa na avaliação do desempenho de classificadores e separadores gravimétricos [8]. Ela permite que o desempenho do separador seja avaliado de maneira relativamente independente da distribuição granulométrica da alimentação, representando, também, uma ferramenta muito útil na simulação do processo.

Resultados típicos de classificação são apresentados na Figura 3. Ela mostra que os valores de imperfeição (dada pela razão entre o intervalo interquartil médio e o tamanho de corte - $\mathrm{d}_{50}$ ) são, surpreendentemente, comparáveis àqueles encontrados em hidrociclones e classificadores helicoidais, quando usados em tarefas semelhantes [9].

A Figura 3 também apresenta os resultados replicados dos ensaios, permitindo a avaliação do erro experimental dos ensaios. A dispersão encontrada se deve, principalmente, a desvios no rendimento do produto grossso $(Y)$. A Figura 3 ainda ilustra, em um dos ensaios, a presença do ponto de inflexão em faixas granulométricas finas, denominado de “anzol” (fish-hook) [4], característico de classificadores aerodinâmicos e de alguns classificadores hidráulicos.

\subsection{Influência de variáveis operacionais no desempenho do classificador}

\section{Efeito da freqüência de rotações}

As Figuras 4 e 5 ilustram a influência da freqüência de rotações no desempenho do classificador. O aumento monotônico do d50 a baixos ângulos das palhetas com a freqüência se deve à maior ação da força centrífuga, uma vez que, nesses ângulos, a ação seletiva das pa-

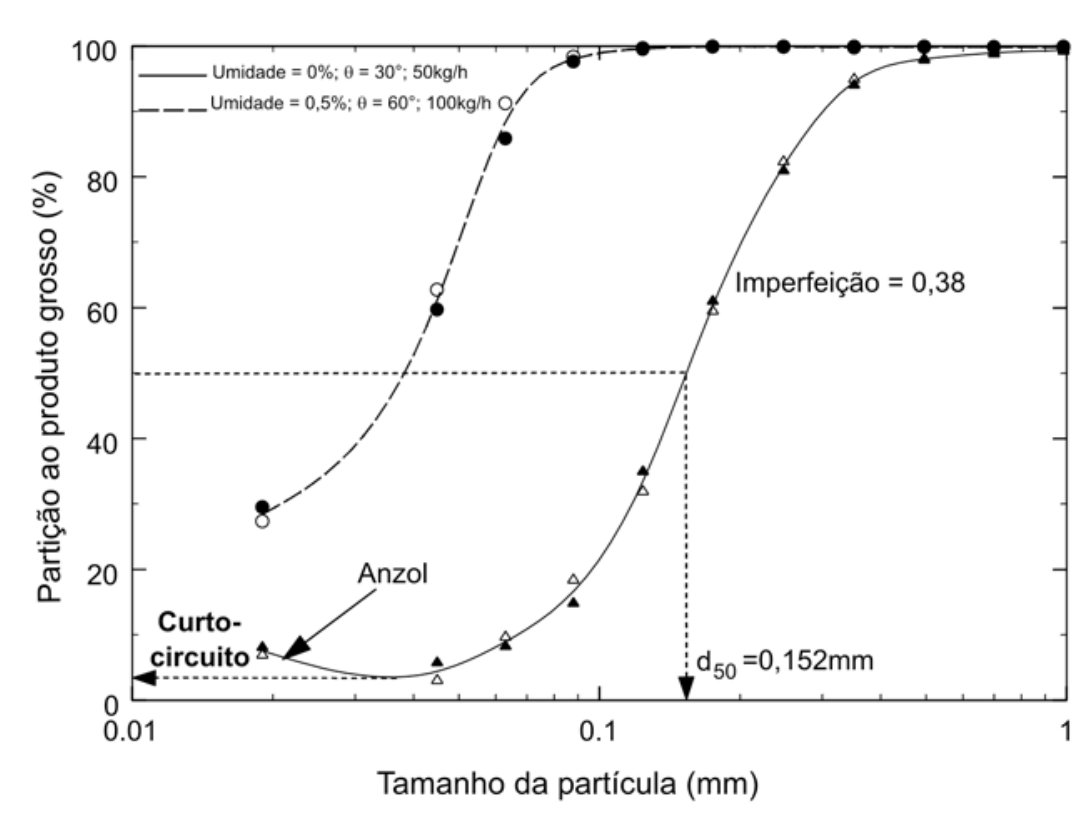

Figura 3 - Curvas de partição de ensaios replicados do classificador processando o produto do britador de impacto a uma freqüência $(\omega)$ de $303 \mathrm{rpm}$, mostrando os parâmetros de avaliação de desempenho.

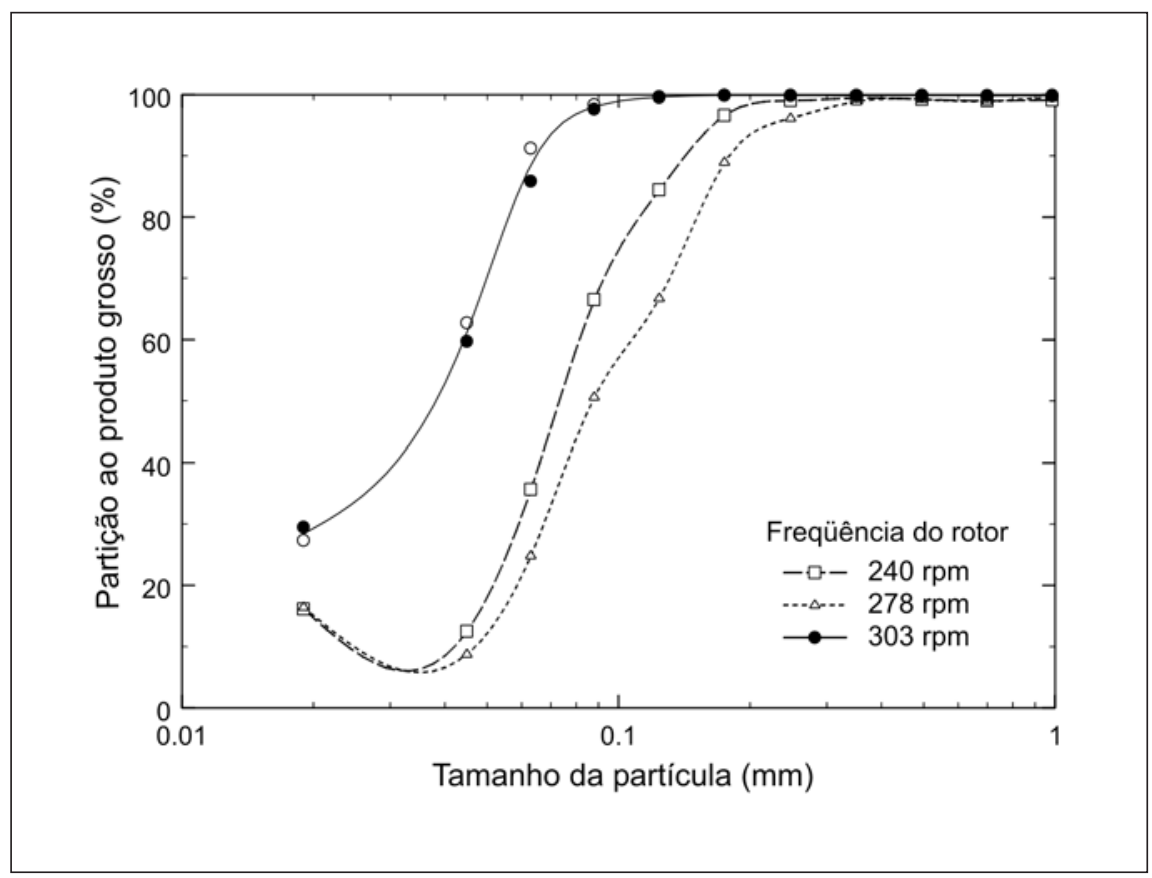

Figura 4 - Efeito da freqüência de rotações na curva de partição do classificador processando o produto do britador de impacto com umidade de $0,5 \%$ a uma taxa de alimentação de sólidos de $100 \mathrm{~kg} / \mathrm{h}( \pm 10 \%)$ e $\theta=60^{\circ}$.

lhetas é muito limitada. Por outro lado, a diminuição significativa observada no d50 para os ensaios com o ângulo $(\theta)$ de $60^{\circ}$ está associada à ação seletiva das palhetas. Esse efeito deve se tornar mais significativo para ângulos maiores, mais usualmente empregados nesse tipo de separador. 


\section{Efeito do ângulo das palhetas}

As Figuras 6 e 7 mostram que, à medida que aumenta o ângulo das palhetas, diminui o tamanho de corte e aumenta o curto circuito para o produto grosso, diminuindo o curto-circuito para o produto fino. Com o aumento do ângulo das palhetas $(\theta)$, mais dificultado se torna o percurso das partículas em torno do rotor, fazendo com que apenas as partículas muito finas reportem ao produto fino do classificador.

\section{Efeito do teor de umidade}

Classificadores aerodinâmicos são notáveis pela sua sensibilidade à presença de umidade na alimentação, a qual se apresenta, freqüentemente, como uma limitante de sua aplicação industrial [1] . A Figura 8 analisa o efeito do teor de umidade no desempenho do classificador Sturtevant. Observa-se que o curtocircuito aumenta de forma significativa com o aumento do teor de umidade. Além disso, observa-se que a imperfeição de separação aumenta a ponto que nenhuma separação ocorre a teores de umidade da ordem de $5 \%$.

Esse efeito se deve ao fato de que a presença de umidade influencia, diretamente, o grau de dispersão do material no interior do separador. A eficiência da classificação a seco, por sua vez, depende, fortemente, desse grau de dispersão. Quando partículas finas sofrem aglomeração e não são adequadamente dispersas no separador, elas tenderão a ser classificadas junto ao produto grosso, ao invés de serem transportadas através do rotor até a descarga dos finos. O resultado é a diminuição significativa do tamanho de corte e o aumento do curto-circuito com o aumento do teor de umidade, o que é observado nas Figuras 8 e 9 .

\section{Efeito da taxa de alimentação}

O aumento da taxa de alimentação, com um fluxo constante de ar, faz com que a concentração de sólidos na suspensão no interior do classificador se

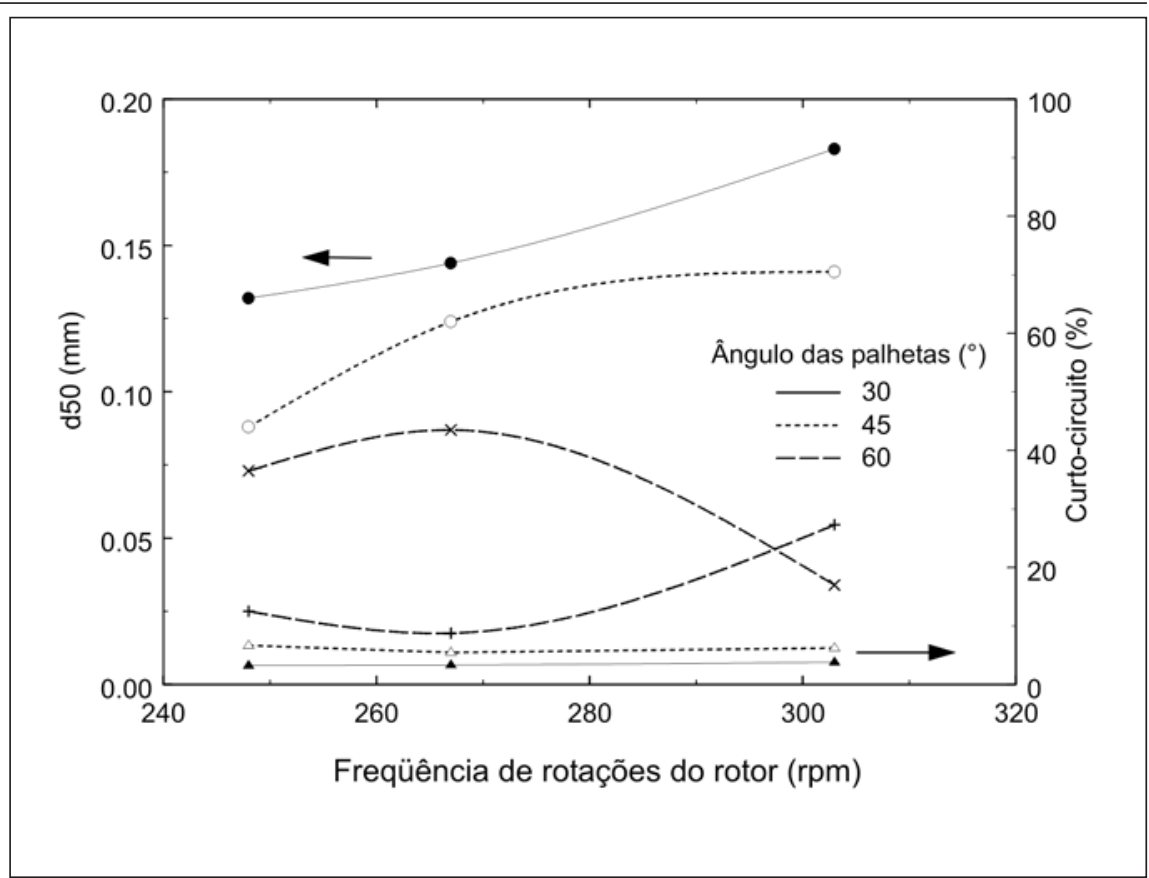

Figura 5 - Efeito da freqüência de rotações no desempenho do classificador processando o produto do britador de impacto com umidade de 0,5\% a uma taxa de alimentação de sólidos de $100 \mathrm{~kg} / \mathrm{h} \pm 10 \%$.



Figura 6 - Efeito do ângulo das palhetas na curva de partição do classificador processando o produto seco do britador cônico a uma taxa de alimentação de sólidos de $180 \mathrm{~kg} / \mathrm{h}( \pm 10 \%)$ e freqüência do rotor de $259 \mathrm{rpm}$.

eleve, o que acarreta um aumento da força de arraste sobre as partículas. O resultado é a diminuição do tamanho de corte com o aumento da taxa de alimen- tação. Kolacz [10] ainda afirma que ocorre um aumento da imperfeição de corte com a concentração de sólidos e, portanto, com a taxa de alimentação. 
A Figura 10 mostra que, dentro do intervalo estudado, a influência da taxa de alimentação no desempenho do classificador é muito limitada. O efeito sugerido por Kolacz é somente observado para o ensaio realizado à taxa de alimentação superior à nominal do aparelho. Adicionalmente, uma influência muito limitada é observada da taxa de alimentação no valor do curto-circuito.

\section{Efeito da forma das partículas}

A influência da forma das partículas é ilustrada na Figura 10, pela comparação dos resultados obtidos com o produto do britador cônico (mais lamelar) e de impacto (mais isométrica). Observase que o tamanho de corte é, em geral, mais baixo para o caso do material com morfologia mais próxima da esférica (produto britador de impacto). Assim, no caso desse material, partículas mais finas são recuperadas com maior facilidade no produto grosso, não sendo arrastadas com a mesma facilidade pelo fluxo de ar que carrega o produto fino. Esse efeito, entretanto, é bastante limitado. Esse efeito também explica os maiores valores de curto-circuito observados para o produto dos britadores cônicos, que apresentam caráter mais lamelar. Ambos efeitos, entretanto, são, comparativamente, pequenos comparados aos demais analisados.

\section{Conclusões}

A investigação da influência das variáveis operacionais no desempenho do classificador aerodinâmico permitiu concluir que:

- A freqüência de rotações exerce alguma influência na separação. Entretanto essa influência depende, sobremaneira, do ângulo das palhetas.

- O ângulo das palhetas exerce uma influência significativa no desempenho, com uma diminuição do tamanho de corte com o aumento do ângulo.

- O teor de umidade influencia, significativamente, o desempenho do clas-



Figura 7 - Efeito do ângulo das palhetas no desempenho do classificador processando o produto seco do britador cônico a uma taxa de alimentação de sólidos de $180 \mathrm{~kg} / \mathrm{h}$ $( \pm 10 \%)$ e freqüência do rotor de $259 \mathrm{rpm}$.

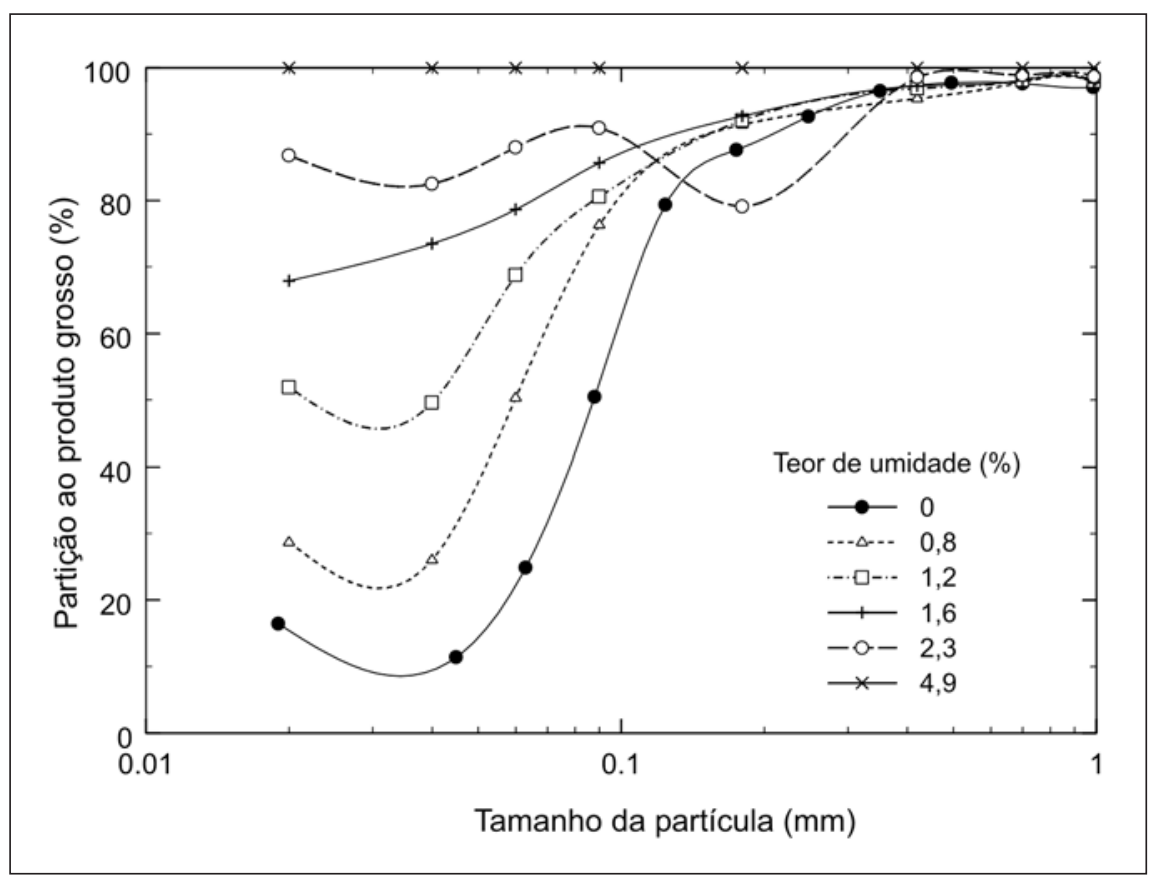

Figura 8 - Efeito do teor de umidade na curva de partição do classificador operando $\operatorname{com} \theta=30^{\circ}$ e processando o produto do britador cônico a uma taxa de alimentação de sólidos de $240 \mathrm{~kg} / \mathrm{h} \pm 10 \%$ e freqüência do rotor de $259 \mathrm{rpm}$.

sificador, com efeitos particularmente grandes observados para teores tão baixos quanto 0,8\% e de tal maneira que nenhuma separação é observada para teores superiores a 5\%.
- Desde que abaixo da capacidade nominal, a taxa de alimentação exerce uma influência muito limitada no desempenho do separador.

- A influência da forma de partícula se mostrou relativamente limitada. 
Luís Marcelo Marques Tavares et al.

\section{Agradecimentos}

Os autores agradecem o auxílio financeiro da FINEP (CT-Mineral), do CNPq e da FAPERJ (CT-Infra).

\section{Referências Bibliográficas}

1. CUNHA, E.R., ALMEIDA, S.L., TAVARES, L.M.M. Desempenho do classificador pneumático Sturtevant na produção de areia artificial. In: Encontro Nacional de Tratamento de Minérios e Metalurgia Extrativa, 20, 2004, Florianópolis, Anais...., v. 1, p. 241-248.

2. JOHANSEN, S.T., SILVA, S.R. Some considerations regarding optimum flow fields for centrifugal air classification, International Journal of Mineral Processing, v. 44-45, p. 703-721, 1996.

3. LUCKIE, P.T., AUSTIN, L.G. Mathematical analysis of mechanical air separator selectivity curves Transactions of the Institution of Mining and Metallurgy, v. 84, C253-C255, 1975.

4. KLUMPAR, I.V. Measuring and optimizing air classifier performance, Separation Technology, v. 2, p. 124-135, 1992.

5. WANG, X., GE, X., Z, X, WANG, Z. A model for performance of the centrifugal countercurrent air classifier, Powder Technology, v. 98, p. 171-176, 1998.

6. NEVES, P.B. Características de fragmentação e microestruturais de rochas e seu comportamento na britagem para a produção de agregado. COPPE/ UFRJ: Programa de Engenharia Metalúrgica e de Materiais, 2005. 129 p. (Dissertação de Mestrado).

7. ALMEIDA, S.L., CUNHA, E.R., TAVARES, L.M.M. Produção de areia artificial em usina-piloto na Pedra Sul Mineração. In: Encontro Nacional de Tratamento de Minérios e Metalurgia Extrativa, 20, 2004, Florianópolis, Anais.... v. 1, p. 105-112.

8. SAMPAIO, C.H., TAVARES, L.M.M. Avaliação de desempenho e simulação. In: Beneficiamento Gravimétrico. Editora da UFRGS, 2005. cap. 12, p. 509541.

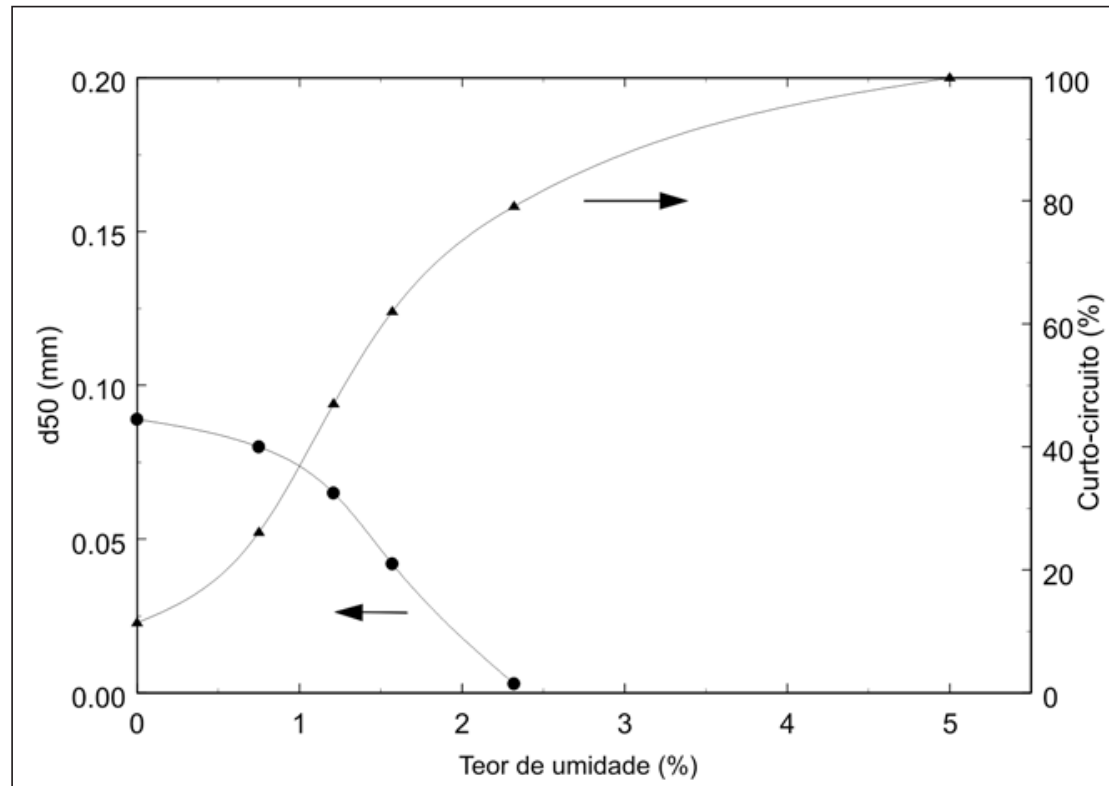

Figura 9 - Efeito do teor de umidade no desempenho do classificador operando com $\theta=30^{\circ}$ e processando o produto do britador cônico a uma taxa de alimentação de sólidos de $240 \mathrm{~kg} / \mathrm{h} \pm 10 \%$ e freqüência do rotor de $259 \mathrm{rpm}$.

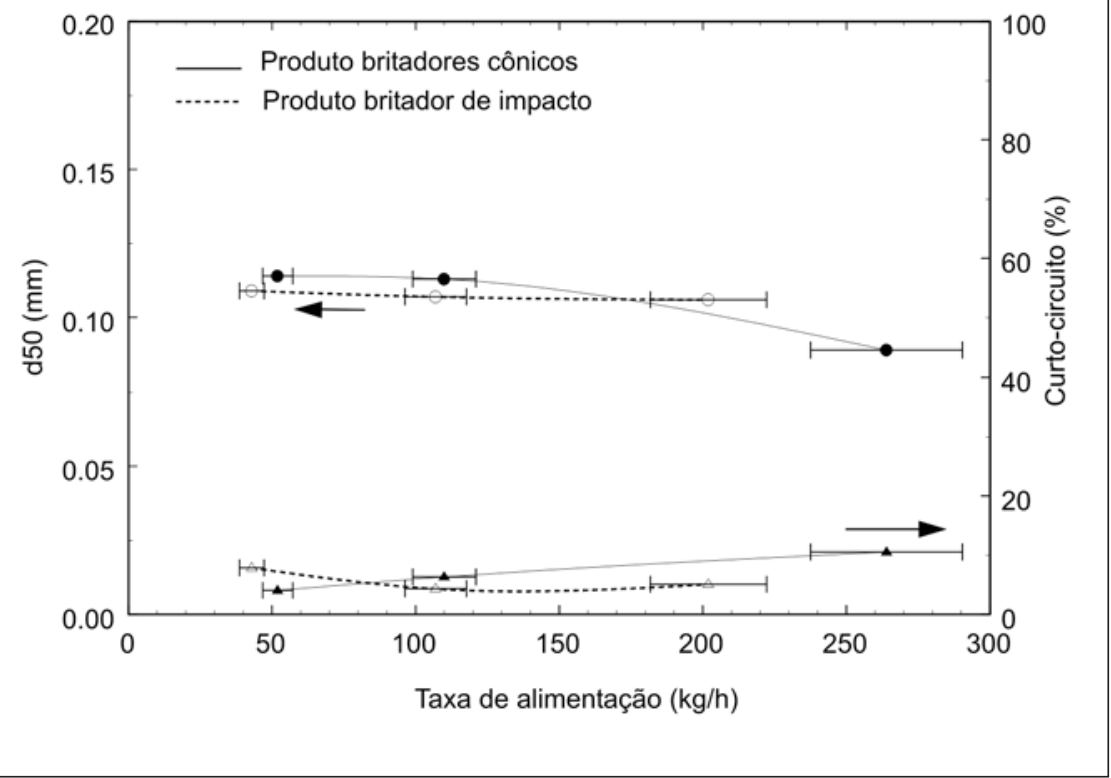

Figura 10 - Efeito da taxa de alimentação e da forma de partículas no tamanho de corte do classificador operando com $\theta=30^{\circ}$ e freqüência do rotor de $259 \mathrm{rpm}$ com o material da alimentação seco.

9. HEISKANEN, K. Particle classification, Chapman and Hall, 1993.

10. KOLACZ, J. Investigating flow conditions in dynamic air classification, Minerals Engineering, v. 15, p. 131-138, 2002.

Artigo recebido em 07/02/2006 e aprovado em 24/01/2007. 